\title{
Nutritional supplementation with arginine protects radiation-induced effects. An experimental study ${ }^{1}$
}

\author{
Flavia Cristina Morone Pinto ${ }^{\mathrm{I}}$, Pamella Campos-Silva ${ }^{\mathrm{II}}$, Diogo Benchimol de Souza ${ }^{\mathrm{III}}$, Waldemar Silva Costa ${ }^{\mathrm{IV}}$, Francisco José \\ Barcellos Sampaiov
}

DOI: http://dx.doi.org/10.1590/S0102-865020160100000002

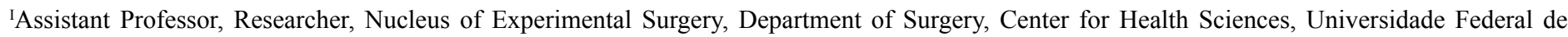
Pernambuco (UFPE), Recife-PE, Brazil. Design of the study, histomorphometrical examinations, statistical analysis, manuscript writing.

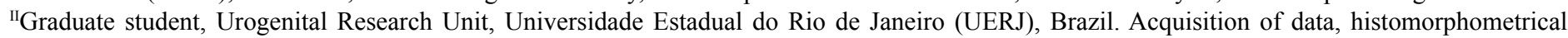
examinations.

IIIAssistant Professor, Researcher, Urogenital Research Unit, UERJ, Rio de Janeiro-RJ, Brazil. Intellectual and scientific content of the study, functional examination.

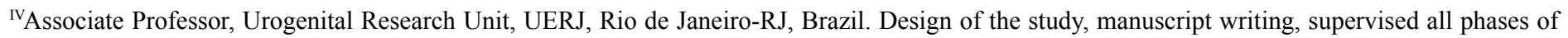
the study.

vFull Professor, CNPq 1A Researcher, Urogenital Research Unit, UERJ, Rio de Janeiro-RJ, Brazil. Intellectual and scientific content of the study.

\section{ABSTRACT}

PURPOSE: To investigate the protective effect of L-arginine on the prostate (nonneoplasic) of rats with radiation-induced injury. METHODS: Twenty-nine Wistar rats, male adult, allocated into three groups: Control group (C) was not exposed to irradiation ( $\mathrm{n}=10$ ); Radiated group $(\mathrm{R})$ had undergone pelvic irradiation $(\mathrm{n}=10)$; Supplemented and radiated group $(\mathrm{R}+\mathrm{S})$ had undergone pelvic irradiation plus L-arginine supplementation $(n=9)$. The animals were observed for signs of toxicity. After euthanization, the prostate was dissected under magnification and stained by hematoxylin and eosin to study acinar structures and stained with Picrosirius red for collagen analysis.

RESULTS: After radiation exposure, all animals presented diarrhea, but supplementation with L-arginine reduced this effect. The weight gain in the $\mathrm{R}+\mathrm{S}$ group was significantly higher than in the $\mathrm{C}$ and $\mathrm{R}$ groups. In the $\mathrm{R}+\mathrm{S}$ group the collagen density and the prostate acinar area was similar to the $\mathrm{R}$ and $\mathrm{C}$ groups. Epithelial height was significantly reduced in group $\mathrm{R}$ compared with group $\mathrm{C}$ $(p<0.0001)$. When comparing the group $\mathrm{R}+\mathrm{S}$ with $\mathrm{R}$, a statistical difference was observed to be present $(\mathrm{p}<0.0001)$.

CONCLUSIONS: Pelvic radiation promotes systemic effects and some structural modifications in the ventral prostate of rats. These modifications can be prevented by oral supplementation with L-arginine.

Key words: Arginine. Radiation Injuries. Rats. 


\section{Introduction}

In recent years, many cytoprotective agents have been developed to protect normal cells from the toxic effects of anticancer chemotherapy and radiotherapy. From a theoretical standpoint, the ideal cytoprotective agent would be capable of maintaining the relative intensity of chemotherapy or a radiotherapy dose, protecting a wider range of organs and preserving antitumor activity, having lower intrinsic toxicity and protecting against free radicals ${ }^{1}$.

On this basis one can hypothesize that L-arginine, by possessing its own mechanisms for inactivation of free radicals produced by irradiation, would be a potentially radioprotective substance. Although the body itself produces L-arginine under certain conditions, such as in infection and in cases of stress, supplementation of these amino acids is essential. L-arginine is a semi-essential amino acid produced in the body, but in insufficient quantity for all needs. In the urea cycle, arginine is used in the synthesis of creatine and ornithine, enabling the synthesis of polyamines $^{2}$.

The radioprotective potential of L-arginine relates to the synthesis of nitric oxide, arising from the oxidation of one of its guanidine nitrogens ${ }^{3}$. Nitric oxide is a potent mediator, with diverse roles in regulating cellular functions and signaling pathways ${ }^{4}$.

The aim of the study was to investigate the protective effect of L-arginine on the prostate (nonneoplasic) of rats with radiation-induced injury.

\section{Methods}

All applicable international, national, and institutional guidelines for the care and use of animals were followed. All procedures performed in studies involving animals were in accordance with the ethical standards of the institution or practice at which the studies were conducted. This research was approved by the Institutional Animal Bioethics Committee of the Biological Sciences Center, Universidade Estadual do Rio de Janeiro (protocol number: CEA/224/2008).

Twenty-nine Wistar rats, male adult (90 days old) were kept in a room with controlled temperature $\left(25 \pm 1^{\circ} \mathrm{C}\right)$, artificial dark-light cycle (lights on from 7:00 am to 7:00 pm) and fed standard rat chow and water ad libitum.

The rats were randomly allocated into three groups: Control group (C) was maintained under standard conditions and was not exposed to irradiation $(n=10)$. Radiated group $(\mathrm{R})$ had undergone pelvic irradiation $(n=10)$ on the eighth day of the experiment. The supplemented and radiated group $(\mathrm{R}+\mathrm{S})$ had undergone pelvic irradiation plus L-arginine supplementation $(n=9)$. This group $(R+S)$ was also exposed to radiation on the eighth day of the experiment and was supplemented with L-arginine (Sigma-Aldrich ${ }^{\circledR}$ ) from the beginning of the experiment (day 0 ) until death. L-arginne was administered by gavage in a dose of $0.65 \mathrm{~g} / \mathrm{Kg}$ of body weight, diluted in distilled water ${ }^{5-8}$.

The animals in the $\mathrm{R}$ and $\mathrm{R}+\mathrm{S}$ groups had each received a single dose of pelvic radiation ${ }^{9}$.

During all experiment stages, the animals were observed for signs of toxicity such as inappetence, weight loss, piloerection, hyper or hypo activity.

All animals were euthanized by an overdose of sodium thiopental on the 22nd day (14 days after radiation exposure).

\section{Stereological analysis}

The prostates were dissected with aid of a stereoscopic microscope, and ventral lobes fixed in $4 \%$ buffered formaldehyde. The specimens were processed for paraffin embedding and sections of $5 \mu \mathrm{m}$ thickness were obtained. Samples were stained by hematoxylin and eosin to study acinar structures and Picrosirius red for collagen analysis.

Micrographs were captured by a digital camera (DP70 Olympus $^{\circledR}$ ) coupled to a light microscope (BX51 - Olympus $\left.{ }^{\circledR}\right)$. All analysis was performed on random fields using Image ${ }^{\circledR}$ software (National Institute of Health, USA).

After calibration, the area of the prostatic acini and epithelium height were measured with "freehand selection" and "straight line selection" tools respectively. The acini area was magnified x200; epithelium height analysis was performed using x1000 magnification.

For collagen analysis, a 100 points grid was superimposed over the images, and the point counting method ${ }^{10-11}$ was used to determine objectively collagen surface density, expressed as a percentage. The analysis was performed using x400 magnification.

\section{Statistical analysis}

For parametric values, both analysis of variance (ANOVA) followed by the Student $t$ test were used. For nonparametric data, both the Kruskal-Wallis test followed by the Mann-Whitney test were used. The GraphPad Prism 5.0 software was used for statistical analysis. The significance level for rejecting the null hypothesis was $5 \%(\mathrm{p} \leq 0.05)$. 


\section{Results}

After radiation exposure, all animals presented diarrhea. Supplementation with L-arginine considerably reduced this effect in approximately $40 \%$ of the animals $(\mathrm{p}=0.0329)$. Over $50 \%$ the animals in the radiated group had nosebleeds. In the supplemented group, $20 \%$ also had nosebleeds. No other toxicity sign was observed.

In the group supplemented with L-arginine $(\mathrm{R}+\mathrm{S})$, the average weight of animals $(313.93 \pm 7.66 \mathrm{~g})$ was different from both the control (C) $(304.56 \pm 18.64 \mathrm{~g})$ and the radiated $(\mathrm{R})$ group (307.00 $\pm 8.42 \mathrm{~g}),(\mathrm{p}=0.0000$ and 0.0004 , respectively).

The weight gain in the $\mathrm{R}+\mathrm{S}$ group (27.65g) was significantly higher than in the $C$ (20.83) and $R$ (3.11) groups ( $p=0.0000$ and 0.0060 , respectively).

Epithelial height was significantly reduced in group $\mathrm{R}$ compared to group $\mathrm{C}(\mathrm{p}<0.0001)$. When comparing the group $\mathrm{R}+\mathrm{S}$ with $\mathrm{R}$, statistical difference was observed $(\mathrm{p}<0.0001)$.

The collagen density between the $\mathrm{C}$ and $\mathrm{R}+\mathrm{S}$ groups showed no statistical difference $(\mathrm{p}=0.1237)$. Collagen was less in group $\mathrm{R}+\mathrm{S}$ when compared with group $\mathrm{R}(\mathrm{p}=0.8674)$, but the values did not differ significantly (Figures 1 and 2).
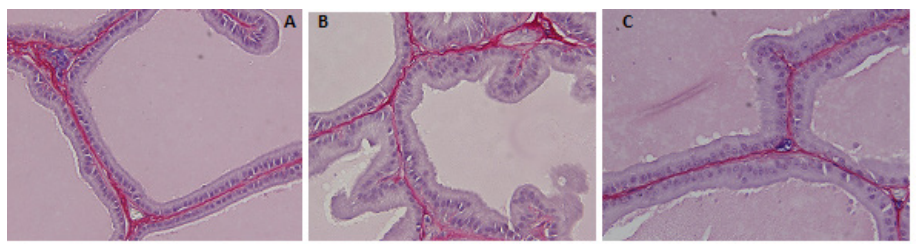

FIGURE 1 - Collagen distribution in the ventral prostate. A: Control; B: Irradiated; C: Irradiated + L-arginine. Picro Sirius [x400].
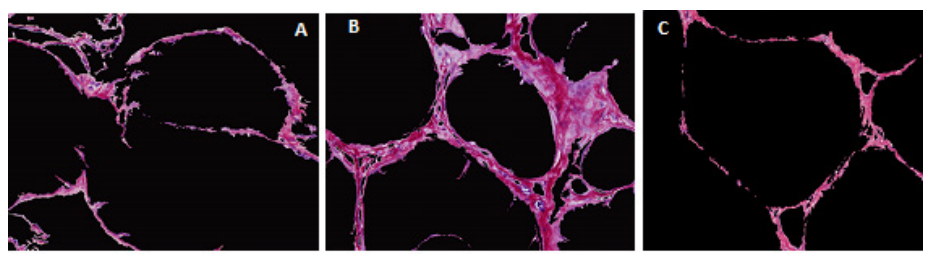

FIGURE 2 - Collagen distribution in the ventral prostate. A: Control; B: Irradiated; C: Irradiated + L-arginine. Picro Sirius [x400]. Computed histophotometry after processing in Adobe Photoshop 6.0 $0^{\circledR}$.

The prostate acinar area of group $\mathrm{R}$ was similar to that of the $\mathrm{C}$ group $(\mathrm{p}=0.9715)$. The $\mathrm{R}+\mathrm{S}$ group had a decrease when compared with the $C(p=0.5648)$ and $R$ groups $(p=0.3470)$, but there was no statistically significant difference.

All data are summarized in Table 1.
TABLE 1 - Morphometric data of ventral prostate from control, radiated and radiated with L-arginine supplementation rats.

\begin{tabular}{cccc}
\hline Parameters & Control & Radiated & $\begin{array}{c}\text { Radiated + L- } \\
\text { arginine }\end{array}$ \\
\hline $\begin{array}{c}\text { Average } \\
\text { weight }(\mathrm{g})\end{array}$ & $304.56 \pm 18.64$ & $307.00 \pm 8.42^{\mathbf{a}}$ & $313.93 \pm 7.66^{\mathbf{a}, \mathbf{b}}$ \\
$\begin{array}{c}\text { Initial Weight } \\
(\mathrm{g})\end{array}$ & $294.20 \pm 16.85$ & $312.00 \pm 19.43$ & $299.95 \pm 16.15$ \\
$\begin{array}{c}\text { Final Weight } \\
(\mathrm{g})\end{array}$ & $315.02 \pm 19.73$ & $315.33 \pm 20.05$ & $327.60 \pm 25.40$ \\
$\begin{array}{c}\text { Weight pon- } \\
\text { deral gain }(\mathrm{g}) \\
\begin{array}{c}\text { Collagen } \\
\text { distribution } \\
(\%)\end{array}\end{array}$ & 20.83 & $3.11^{\mathbf{a}}$ & $27.65^{\mathbf{a}, \mathbf{b}}$ \\
$\begin{array}{c}\text { Acini area } \\
\left(\mu m^{2} .10^{3}\right)\end{array}$ & $78.3 \pm 5.2$ & $78.6 \pm 2.8$ & $74.4 \pm 4,4$ \\
$\begin{array}{c}\text { Epithelial } \\
\text { height }(\mu \mathrm{m})\end{array}$ & $18.31 \pm 1.9$ & $11.59 \pm 0.8^{\mathbf{a}}$ & $19.76 \pm 5.6^{\mathbf{b}}$ \\
\hline
\end{tabular}

Note: Values represent in \% (chi-square test) and mean \pm SD (t test Student unpaired). $\mathrm{p}>0.05$. $\mathrm{a} \neq$ Control group; $\mathrm{b} \neq$ Radiated group .

\section{Discussion}

Pelvic radiation is well recognized as a cause of major side effects contributing to morbidity of oncologic patients.

One of the consequences of the radiation-matter interaction on cell structures is the production of a reactive oxygen species and oxidative damage. The immediate effects of radiation can be easily observed in tissues with great proliferative capability, such as the epithelium, leading to vascular injuries, hypoxia, and cell death ${ }^{12}$.

In recent years, L-arginine supplementation or restriction has been proposed and trialed in for a number of disorders, including vascular diseases and asthma, mitochondrial encephalopathy lactic acidosis and stroke-like episodes (MELAS), glutaric aciduria type I and disorders of creatine metabolism, both in production and transportation into the central nervous system ${ }^{13}$.

Supplementation with L-arginine was shown to have systemic protective effects, since it reduced radiation-induced diarrhea in approximately $40 \%$ of the animals, maintained body weight and increased weight gain. In another study, the authors also reported cases of diarrhea with oral supplementation of L-arginine ${ }^{13}$.

Possibly the systemic protective effects of oral supplementation with L-arginine are related to their ability to act in various systems such as cardiovascular, endocrine-metabolic and kidney, promoting, for example, stimulation of insulin secretion, 
growth hormone and reduction of angiotensin-converting enzyme activity. These beneficial effects have been associated with improvement in endothelial function with increased production of endothelium-derived relaxing factors ${ }^{14}$.

With specific reference to the prostate, radiation promoted a significant change in the acinar epithelium height, decreasing it by approximately $36 \%$ when compared to the control group and $41 \%$ for the supplemented group. This modification corroborates with what was previously pointed ${ }^{12}$.

Studies in rats showed that L-arginine protected vesical modifications, alterations in penile structures after pelvic radiation $^{15}$, acting against oxidative damage ${ }^{16-18}$. However, there is a lack of information regarding L-arginine in preserving and maintaining the integrity of the prostate after pelvic radiotherapy. The present study establishes through quantitative methods the benefits of oral supplementation with L-arginine for protecting the prostate from radiation.

Supplementation with L-arginine regenerated the acinar epithelium, as confirmed by the statistical difference between this group and the irradiated group, as well as between it and the control. According to Cukier ${ }^{16}$, L-arginine is the major oxidative fuel for the epithelial cells, consisting of an oxidizable amino acid precursor, a nitric oxide and polyamines, as well as being associated with the metabolism of urea.

Oxidative stress is detrimental to animals and the arginine may function as a potential substance against oxidative stress, through the enhancement of antioxidant capacity and inhibition of the expression of inflammatory cytokines (IL-6 and TNF-a mRNA) $)^{17}$.

The effects of L-arginine supplementation on human physiology appear to be multicausal and dose-related. Doses of 3-8 g/day appear to be safe and not to cause acute pharmacological effects in humans ${ }^{18}$. In this study, the L-arginne was administered by gavage in a dose of $0.65 \mathrm{~g} / \mathrm{Kg}$ of body weight.

According to histomorphometric data, radiation significantly affected the rat prostate. After supplementation with L-arginine, there was a significant increase in the height of the epithelium and a decrease, not statistical, in collagen distribution. The acinar area was similar to the control.

Intravenous or dietary (oral) administration of relatively large doses of L-arginine has been shown to result in enhanced nitric oxide formation in individuals with impaired endothelial function at baseline. Recently, it became clear that endogenous levels of asymmetric dimethylarginine (ADMA), a competitive inhibitor of L-arginine metabolism by nitric oxide, might determine an individual's response to L-arginine supplementation.
L-arginine appears to exert no effect in individuals with low ADMA levels, whereas in those with high levels, L-arginine restores the L-arginine/ADMA ratio to normal and, thereby, normalizes endothelial function ${ }^{18}$.

In another study, when L-arginine was used, the authors concluded that pelvic radiation leads to significant vesical modifications, as in the morphology of blood vessels and in VEGF and FGF expression in the wall of rat bladder. All these changes, however, were prevented by L-arginine treatment. The authors emphasized the potential use of this amino acid as a radioprotective $\operatorname{drug}^{19}$.

In addition to the radioprotective effect, L-arginine supplementation has demonstrated protective effects related to reduced dapsone-induced methemoglobin levels. This effect is mediated by nitric oxide formation, since the reduction in methemoglobin levels by L-arginine is blocked by simultaneous administration with L-NAME, a nitric oxide synthase inhibitor ${ }^{20}$.

It is possible that an analysis of the effects of pelvic radiation in prostate rats made over longer periods than that used in this study, 21 days, could result in more drastic changes than those observed in this work.

Also with respect to the radioprotective results of this study, many studies have shown that L-arginine has a protective effect on the radiation-induced injury in several systems (urogenital, skin tissue, immune, cardiac and intestinal mucosa), as can be observed in Supplement 1.

\section{Conclusions}

The pelvic radiation promotes systemic effects and some structural modifications in the ventral prostate of rats. These modifications can be prevented by oral supplementation with L-arginine.

\section{References}

1. Souza CA, Vigorito AC, Aran FJP, Oliveira GB, Eid KAB, Ruiz MA. Terapêutica citoprotetora em pacientes tratados com quimio e/ou radioterapia anti neoplásica. Rev Bras Hematol Hemoter. 2000;22(2):123-8. doi: 10.1590/S1516-84842000000200008.

2. Konturek SK, Konturek PC. Role of nitric oxid in the digestive system. Digestion. 1995;56:1-13. PMID: 7895925.

3. Pereira AC, Paulo M, Araújo AV, Rodrigues GJ, Bendhack LM. Nitric oxide synthesis and biological functions of nitric oxide released from ruthenium compounds. Braz J Med Biol Res. 2011;44(9):947-57. doi: 10.1590/S0100-879X2011007500084.

4. Shinde UA, Mehta AA, Goyal RK. Nitric oxide: a molecule of the millennium. Indian J Exp Biol. 2000;38(3):201-10. PMID: 10927860.

5. Moura JRSA de, Sass N, Guimarães SB, Vasconcelos PRL de, Mattar R, Kulav Jr L. Effects of L-arginine oral supplements in pregnant 
spontaneously hypertensive rats. Acta Cir Bras. 2006;21(4):192-6. doi: 10.1590/S0102-86502006000400001.

6. Hwang J-M, Chan DE-C, Chang T-M, Tsao T-YI, Tsou S-S, Lu R-H, Tsai L-M. Effects of oral arginine and glutamine on radiationinduced injury in the rat. J Surg Res. 2003;109:149-54. doi: 10.1016/ S0022-4804(02)00096-3.

7. Seçilmi MA, Karata Y, Yorulmaz Ö, Büyükafar K, Ingirik E, Doran F, Inal TC, Dikmen A. Protective effect of L-arginine intake on the impaired renal vascular responses in the gentamicin-treated rats. Nephron Physiol. 2005;100:13-20. doi: 10.1159/000084657.

8. Yanni AE, Margaritis E, Liarakos N, Pantopoulou A, Polakou M, Kostakis M, Perrea D, Kostakis A. Time-dependent alterations in serum NO concentration after oral administration of L-arginine, L-NAME, and allopurinol in intestinal ischemia/reperfusion. Vasc Health Risk Manag 2008;4(2):437-41. doi: 10.2147/VHRM.S2433.

9. Diestel CF, Lopes-Paulo F, Marques RG, Horsts NL, Caetano CE. Effect of oral supplement of l-glutamine in colonic wall of rats subjected to abdominal irradiation. Acta Cir Bras. 2005;20(suppl. 1):139-45. doi: 10.1590/S0102-86502005000700017.

10. Oberholzer M, Ostreicher M, Christen H, Brühlmann M. Methods in quantitative image analysis. Histochem Cell Biol. 1996;105(5):33355. PMID: 8781988.

11. Pereira-Sampaio M, Favorito LA, Henry R, Sampaio FJ. Proportional analysis of pig kidney arterial segments: differences from the human kidney. J Endourol. 2007;21(7):784-8. doi: 10.1089/end.2006.0318.

12. Stone HB, Coleman CN, Anscher MS, McBride WH. Effects of radiation on normal tissue: consequences and mechanisms. Lancet Oncol. 2003;4(9):529-36. doi: 10.1016/S1470-2045(03)01191-4.

13. Coman D, Yaplito-Lee J, Boneh A. New indications and controversies in arginine therapy. Clin Nutr. 2008;27(4):489-96. doi: 10.1016/j. clnu.2008.05.007.

14. Puga GM, Novais IP, Zanesco A. Efeitos terapêuticos da suplementação de L-arginina nas doenças cardiovasculares e endócrino-metabólicas. Arq Med. 2011;25(3):107-14.

15. Medeiros JL Jr, Costa WS, Felix-Patricio B, Sampaio FJ, Cardoso LE. Protective effects of nutritional supplementation with arginine and glutamine on the penis of rats submitted to pelvic radiation. Andrology. 2014;2(6):943-50. doi: 10.1111/andr.134.

16. Cukier RI. A molecular dynamics study of water chain formation in the próton-conducting $\mathrm{K}$ channel of citochrome $\mathrm{C}$ oxidase. Biochim Biophys Acta. 2005;7:1706(1-2): 134-46. doi: 10.1016/j. bbabio.2004.10.004.

17. Zheng P, Yu B, He J, Tian G, Luo Y, Mao X, Zhang K, Che L, Chen D. Protective effects of dietary arginine supplementation against oxidative stress in weaned piglets. Br J Nutr. 2013;28;109(12):225360. doi: 10.1017/S0007114512004321.
18. Böger RH. The pharmacodynamics of L-arginine. Altern Ther Health Med. 2014;20(3):48-54. PMID: 24755570.

19. Costa WS, Ribeiro MN, Cardoso LE, Dornas MC, Ramos CF, Gallo CB, Sampaio FJ. Nutritional supplementation with L-arginine prevents pelvic radiation-induced changes in morphology, density, and regulating factors of blood vessels in the wall of rat bladder. World J Urol. 2013;31(3):653-8. doi: 10.1007/ s00345-012-0938-6.

20. Moraes NV, Bergamaschi MM, Bianchi MLP, Bragheto JB, Malfará WR, Queiroz RHC. L-arginine, a nitric oxide precursor, reduces dapsone-induced methemoglobinemia in rats. Braz J Pharm Sci. 2012;48(1):87-94. doi: 10.1590/S1984-82502012000100010

\section{Acknowledgements}

To Department of Radiotherapy of the University Center for Cancer Control (CUCC/UERJ), and Sidney Pratt, Johns Hopkins University, RSA diploma (TEFL) for revision of the English version of this text.

\section{Correspondence:}

Flávia Cristina Morone Pinto

Núcleo de Cirurgia Experimental, Departamento de Cirurgia Centro de Ciências da Saúde, UFPE

Avenida Professor Moraes Rego, 1235 / Cidade Universitária 50670-901 Recife - PE Brasil

Tel.: (55 81)2126-8519

fcmorone@gmail.com

Received: Jun 12, 2016

Review: Aug 15, 2016

Accepted: Sep 18, 2016

Conflict of interest: none

Financial sources: CNPq, FAPERJ, and CAPES

${ }^{1}$ Research performed at Urogenital Research Unit, Universidade Estadual do Rio de Janeiro (UERJ), Brazil. Part of PhD degree thesis, Postgraduate Program in Pathophysiology and Surgical Sciences, UERJ. Tutor: Francisco José Barcellos Sampaio. 